\title{
Differential Risky Behaviors among HIV Positive and HIV Negative People
}

\section{Céline Nguefeu Nkenfou ${ }^{1,2 *}$, Josiane Gouekem ${ }^{3}$, Antoine Socpa $^{4}$, Blandine Nkenfou Kampa $^{3}$, Elvis Ndukong $\mathrm{Ndzi}^{1,5}$, Alexandre $\mathrm{Nkoum}^{3}$ and Alexis Njolo ${ }^{1,6}$}

${ }^{1}$ Chantal Biya International Reference Centre for HIV/AIDS Prevention and Management, Yaounde, Cameroon

${ }^{2}$ Higher Teachers' Training College, University of Yaounde I, Yaounde, Cameroon

${ }^{3}$ Catholic University of Central Africa, Yaounde, Cameroon

${ }^{4}$ Faculty of Arts and Social Sciences, University of Yaounde I, Yaounde, Cameroon

${ }^{5}$ Faculty of Sciences, University of Dschang, Dschang, Cameroon

${ }^{6}$ Faculty of Medicine and Biomedical Sciences, University of Yaounde I, Yaounde, Cameroon

*Corresponding author: Céline Nguefeu Nkenfou, Professor, Chantal Biya International Reference Centre for HIV/AIDS Prevention and Management; Higher Teachers' Training College, University of Yaounde I, Yaounde, Cameroon, Tel: +23775-57-35-19, E-mail: nkenfou@yahoo.com

\begin{abstract}
Background: In the past years, HIV prevention efforts have increased with focus on people living with HIV and AIDS (PLWHA) in addition to addressing risk reduction efforts targeting HIV-uninfected individuals. HIV prevalence is $6.3 \%$ in Yaounde. This prevalence calls for improvement of prevention strategies. In Cameroon, sensitization activities are continuous and preventive strategy is directed towards HIV negative people. We assessed the suitability of positive prevention in Cameroon, through the comparison of risky behaviors between HIV infected and non-infected people.
\end{abstract}

Methods: HIV positive and HIV negative people were recruited in the capital city of Cameroon. Data were collected through a structured questionnaire, pretested and validated, before and after the knowledge of HIV status. The information collected include: Age at first sexual intercourse, number of sexual partners, usage of condoms and frequency of sexual intercourses.

Results: A total of 320 participants were enrolled, among which 162 People living with HIV (of which $67.3 \%$ female) and 158 HIV sero-negative/ignorant people (of which $63.92 \%$ female). $18.3 \%$ of PLWHA reported having sex before the age of 15 against $10.8 \%$ of HIV sero-negative/ignorant people $(p=0.001)$. PLWHA had more sexual partners than HIV sero-negative/ignorant before and after the knowledge of their HIV status ( $P=0.000$ and $p=0.001$ respectively). Among PLWHA, 39.2\% never used condoms before starting treatment against $15.3 \%$ of HIV negative $(p=0.000)$. Before being aware of their HIV status, PLWHA used less condoms than HIV sero-negative/ignorant $(p=0.000)$. After the awareness of their status, there was no significant difference $(p=0.37)$ in condoms usage in the two groups, implying risk reduction among PLWHA.

Conclusions: PLWHA present more risky behavior than HIV-negative and HIV ignorant. Thus positive prevention strategies could be developed and implemented in Cameroon. Furthermore, given the improved use of condoms by PLWHA after awareness of their HIV status, we foresee success in positive prevention.

\section{Keywords}

Sexual risk behavior, HIV positive, HIV sero-negative/ignorant, Yaounde

\section{List of Abbreviations}

ART: Antiretroviral Treatment; PLWHA: People Living With HIVIAIDS; CNLS: Comité National de Lute contre le Sida; EDS-MICS: Enquête Démographique et de Santé et à Indicateurs Multiples; CDC: Centre for Diseases Control; UNICEF: United Nations Children's Fund; UNAIDS: Joint United Nations Programme on HIVIAIDS; HIV: Human Immunodeficiency Virus; AIDS: Acquired Immune Deficiency Syndrome; WHO: World Health Organization; UPEC: Unité de Prise En Charge; CTA: Centre de Traitement Agrée; SPSS: Statistical Package for the Social Sciences

Citation: Nkenfou CN, Gouekem J, Socpa A, Kampa BN, Ndzi EN, et al. (2017) Differential Risky Behaviors among HIV Positive and HIV Negative People. Int J Virol AIDS 3:037. doi.org/10.23937/2469567X/1510037

Received: September 07, 2017: Accepted: December 26, 2017: Published: December 28, 2017 Copyright: (c) 2017 Nkenfou CN, et al. This is an open-access article distributed under the terms of the Creative Commons Attribution License, which permits unrestricted use, distribution, and reproduction in any medium, provided the original author and source are credited. 


\section{Introduction}

Since the first cases of AIDS in Cameroon in 1985, the Government has made the fight against HIV and AIDS a national priority. This commitment was materialized by the implementation of emergency plans to fight against HIV and AIDS and three generations of National Strategic Plans (2000-2005, 2006-2010 and 2011-2015) [1-3]. This proactive policy of the Government, with the support of partners and the effective involvement of the private sector, civil society, faith-based organizations and people living with HIV, has led to concrete results, including available HIV prevention services, free and voluntary HIV testing and support for people infected and affected by this pandemic.

The knowledge level of the population has increased considerably and HIV prevalence in the general population has decreased since the 2004 [4,5]. According to the EDS-MICS 2011, in Cameroon, 4.3\% of adults aged 15-49 are HIV positive. Between 2005 and 2009, there was an increase in the national geographic coverage in support structures from $36 \%$ to $56 \%$ and a coverage rate of $23 \%$ to $46.5 \%$ for ARV [6].

Progress is noticeable in terms of prevention, coordination and management of interventions against AIDS in Cameroon, but many gaps still remain. Cameroon is still in generalized epidemic (5.1\% prevalence in the general population in 2009 and $4.3 \%$ in 2011), with high prevalence in specific groups (pregnant women, 7.6\%; sex workers, 36.8\%, "men in uniform" (militaries, gendarmes and policemen), $11.2 \%$ [6]. In addition, many services needs remain unmet by the end of 2009. For example in prevention, only $13 \%$ of the population (15-49 years) knows their HIV status, $31 \%$ and $13 \%$ respectively of the need in condoms and safe blood are covered. In terms of treatment, less than $20 \%$ of children and less than $50 \%$ of eligible adult patients have access to Antiretrovirals (ARV) treatment (CNLS, 2013) [6]. In this paper, we are focusing on the gap in the prevention strategy.

As more and more people infected with HIV live healthier and enjoy longer lives thanks to ARVs [7], an increase in HIV transmission may come from those who know they are infected and engage in unprotected sex.

It is therefore very important to establish the risky behavior in HIV infected people and to understand the factors that contribute to risky practices in PLWHA in order to design optimal interventions targeting HIV-positive people. These interventions called positive prevention [8-14] can be a cost effective approach to reduce HIV transmission.

Positive prevention has been recommended by UNAIDS and has been implemented in industrialized countries [15-17] and would be beneficial for developing countries including Cameroon to implement this strategy that has been proven effective in other countries.

Worldwide and particularly in developing countries, HIV prevention is mainly concentrated on reducing the risk of HIV acquisition, so focusing primarily on non-infected people or people who are unaware of their HIV status [18]. With this strategy, high prevalence of HIV still prevailed in some parts of the world such as Cameroon; proving the drawbacks of this strategy. It is well known that ARV reduce the risk of HIV transmission, but it has also been shown that the availability of ARV increase the risky behaviors of PLWHA [19]. Only people living with HIV can transmit HIV. Preventive interventions targeting them (the 'positive prevention') help reduce their risk of transmission based on the principles of epidemiology of infectious diseases that focus on infectious source $[20,21]$. It is important or imperative to develop new prevention strategies that involve the participation of this category of persons. Can positive prevention be applied in Cameroon? Before getting there, what is the level of HIV risk behaviors among PLWHA compared to HIV sero-negative/sero-ignorant in Yaounde?

\section{Methods}

We conducted a cross sectional study where data were collected to compare the risky behaviors between PLWHA and HIV sero-negative/sero-ignorant people in Yaounde, Cameroon.

Research participants were recruited in the HIV care units- "Unité de Prise En Charge (UPEC)", in authorized treatment centers ("CTA") and in some health facilities of Yaounde (Yaounde military hospital, Central Hospital, University Teaching Hospital and Olembé district hospital). Data were collected through a questionnaire, tested and validated. Questionnaire-assisted interview was administered in french and/or english. This questionnaire included socio-demographic information, condoms usage, age at first sex, number of sexual partners and frequency of sex.

\section{Statistical Analyses}

Data were entered into Epi Info version 7 and analyzed using Excel and SPSS 18.0 software. Univariate analyses were conducted to assess the quality and capacity of variables to be associated with risk behaviors of HIV among people living with HIV/AIDS. Then a bivariate analysis was done to search for associations between these variables. The level of significance of our findings was set at $95 \%$ with error margin of $5 \%(0.05)$.

\section{Results}

\section{Socio-demographic characteristics of participants}

Our study targeted 320 participants who have resided for at least six months in the city of Yaounde. 162 HIV-positive and 158 HIV sero-negative/sero-ignorant participants, were surveyed in five health facilities in Yaounde. They were all subjected to the same questionnaire regardless of their HIV status.

The age group 20 to 34 years accounted for $71.5 \%$ of 
Table 1: Socio-demographic characteristics of the study population.

\begin{tabular}{|c|c|c|c|c|}
\hline Characteristics & Total N (\%) & PLWHA N (\%) & HIV negatives/ignorants $\mathrm{N}(\%)$ & $P$ value \\
\hline Age & $318(99.4 \%)$ & $162(50.94 \%)$ & $156(49.06 \%)$ & 0.000 \\
\hline Mean \pm std & & $36.68 \pm 7.85$ & $27.46 \pm 7.27$ & \\
\hline Min & & 16 & 16 & \\
\hline Max & & 55 & 55 & \\
\hline Sex & $318(99.4 \%)$ & $160(50.31 \%)$ & $158(49.69 \%)$ & 0.303 \\
\hline M & & $53(32.7 \%)$ & $57(36.08 \%)$ & \\
\hline $\mathrm{F}$ & & $109(67.3 \%)$ & $101(63.92 \%)$ & \\
\hline Education level & $320(100 \%)$ & $162(50.60 \%)$ & $158(49.40 \%)$ & 0.000 \\
\hline No education & & $6(3.7 \%)$ & $4(2.53 \%)$ & \\
\hline Primary & & $67(41.3 \%)$ & $14(8.86 \%)$ & \\
\hline Secondary & & $71(43.8 \%)$ & $64(40.51 \%)$ & \\
\hline University & & $18(11.1 \%)$ & $76(48.10 \%)$ & \\
\hline Job & $318(99.4 \%)$ & $160(50.31 \%)$ & $158(49.69 \%)$ & 0.005 \\
\hline Jobless & & $72(45 \%)$ & $95(60.13 \%)$ & \\
\hline With a job & & $88(55 \%)$ & $63(39.87 \%)$ & \\
\hline Matrimonial status & $318(99.4 \%)$ & $160(50.31 \%)$ & $158(49.69 \%)$ & 0.000 \\
\hline Married & & $45(28.12 \%)$ & $35(22.15 \%)$ & \\
\hline Free union & & $36(22.50 \%)$ & $26(16.45 \%)$ & \\
\hline Bachelors & & $56(35.0 \%)$ & 97 (61.39\%) & \\
\hline Widowers & & $14(8.75 \%)$ & $0(00 \%)$ & \\
\hline Separated & & $9(5.62 \%)$ & $0(00 \%)$ & \\
\hline Religion & $320(100 \%)$ & $162(50.60 \%)$ & $158(49.40 \%)$ & 0.615 \\
\hline Catholic & & $96(59.2 \%)$ & $98(62.03 \%)$ & \\
\hline Protestant & & $27(16.6 \%)$ & $32(20.25 \%)$ & \\
\hline Muslim & & $7(4.3 \%)$ & $4(2.53 \%)$ & \\
\hline Other religion & & $26(16.0 \%)$ & $18(11.39 \%)$ & \\
\hline No religion & & $6(3.7 \%)$ & $6(3.80 \%)$ & \\
\hline
\end{tabular}

Table 2: Age at first sexual activity and HIV serostatus.

\begin{tabular}{|l|l|l|}
\hline & HIV sero-positives & Sero-negatives/sero-ignorants \\
\hline Age at first sex $\mathrm{N}=311$ & $\mathbf{1 5 3}(\mathbf{4 9 . 2} \%)$ & $\mathbf{1 5 8}(\mathbf{5 0 . 8 \% )}$ \\
\hline$<\mathbf{1 1}$ & $2(1.3 \%)$ & $1(0.6 \%)$ \\
\hline $\mathbf{1 1 - 1 5}$ & $28(18.3 \%)$ & $17(10.8 \%)$ \\
\hline $\mathbf{1 5 - 1 9}$ & $96(62.7 \%)$ & $84(53.1 \%)$ \\
\hline $\mathbf{2} \mathbf{2 0}$ & $27(17.6 \%)$ & $45(28.5 \%)$ \\
\hline Never had sex & $0(00.0 \%)$ & $11(7.0 \%)$ \\
\hline & & \\
\hline PLWHA on ART & $\mathrm{N}=161$ & \\
\hline Yes & $148(91.9 \%)$ & \\
\hline No & $13(8.1 \%)$ & \\
\hline
\end{tabular}

the sample of HIV-negative and HIV-sero-ignorant that we included in our study. $12.0 \%$ were under 20 , while $16.5 \%$ were 35 and over.

For PLWHA, The age group 25 to 44 and over accounted for $72.8 \%$. A percentage of 5.6 were aged under 25, while $21.6 \%$ were 45 and over. $60.6 \%$ were catholic overall (Among PLWHA, 59.2\% were catholic). A portion (52.5\%) were jobless, $19.49 \%$ were in free union, $25.15 \%$ were married and $48.11 \%$ were bachelors. 3.12\% were illiterate and $29.37 \%$ had reached university education level. These data are presented in Table 1 . There was a strong relation between the age, the education level, the occupation, the matrimonial status and the HIV sero-status ( $p=0.0,0.0,0.005$ and 0.0 respectively). There was no relationship between the HIV sero-status and the religion $(p=0.615)$.

\section{Age at first sexual activity}

In the group of HIV sero-negative/sero-ignorant, 53.1\% had their first intercourse between 15 and 19 years; $11.4 \%$ before 15 , while $28.5 \%$ had their first sex as from 20 -yearsold. In this group, $7.0 \%$ had not yet had sex. Meanwhile, in the group of people living with HIV, $62.7 \%$ had their first sexual activity between the age of 15 and 19 years; $19.6 \%$ had it before 15 , while 17.6 had it after 20 -years-old. There was an association between the age at first sexual activity and the HIV sero-status ( $p=0.001$ ). The early the first sexual intercourse, the higher was the risk to acquire HIV infection, see Table 2. Nationwide, the reported average age at first sexual activity is 18-years-old [21].

\section{Condom use before being aware of HIV status}

Among HIV sero-negative/sero-ignorant that we questioned, $15.3 \%$ said they never use condoms during their 
Table 3: Comparison of HIV risky behaviors before and after awareness of status in sero-positives and sero-negatives/sero-ignorants.

\begin{tabular}{|c|c|c|c|c|c|c|c|}
\hline \multirow{2}{*}{\multicolumn{2}{|c|}{ Risky behaviors }} & \multicolumn{3}{|l|}{ Sero-positives } & \multicolumn{3}{|c|}{ Sero-negatives/sero-ignorants } \\
\hline & & \multirow{2}{*}{$\begin{array}{l}\text { Before awareness } \\
62(39.2 \%)\end{array}$} & \multicolumn{2}{|c|}{ After awareness P-value } & \multirow{2}{*}{$\begin{array}{l}\text { Before awareness } \\
22(15.3 \%)\end{array}$} & \multirow{2}{*}{\begin{tabular}{|l|} 
After awareness \\
$28(18.9 \%)$
\end{tabular}} & \multirow{2}{*}{ P-value } \\
\hline \multirow[t]{4}{*}{ Condom usage } & Never & & $24(16.1 \%)$ & \multirow{4}{*}{0.002} & & & \\
\hline & Often & $85(53.8 \%)$ & $63(42.3 \%)$ & & $77(53.5 \%)$ & $70(47.3 \%)$ & \multirow{3}{*}{0.000} \\
\hline & Always & $11(7.0 \%)$ & $62(41.6 \%)$ & & $45(31.3 \%)$ & $50(33.8 \%)$ & \\
\hline & Total & $158(100.0 \%)$ & $149(100.0 \%)$ & & $144(100.0 \%)$ & $148(100.0 \%)$ & \\
\hline \multirow{7}{*}{$\begin{array}{l}\text { Number of } \\
\text { sexual partners }\end{array}$} & No partner & $2(1.3 \%)$ & $22(13.8 \%)$ & \multirow{7}{*}{0.001} & $17(10.8 \%)$ & $16(10.1 \%)$ & \multirow{7}{*}{0.000} \\
\hline & 1 partner & $65(40.6 \%)$ & $93(58.1 \%)$ & & $95(60.1 \%)$ & $125(79.1 \%)$ & \\
\hline & 2 partners & $50(31.3 \%)$ & $29(18.1 \%)$ & & $31(19.6 \%)$ & $14(8.9 \%)$ & \\
\hline & 3-4 partners & $30(18.8 \%)$ & $12(7.5 \%)$ & & $13(8.2 \%)$ & $3(1.9 \%)$ & \\
\hline & 5-9 partners & $4(2.5 \%)$ & $2(1.3 \%)$ & & $1(0.6 \%)$ & $0(00 \%)$ & \\
\hline & $\geq 10$ partners & $9(5.6 \%)$ & $2(1.3 \%)$ & & $1(0.6 \%)$ & $0(00 \%)$ & \\
\hline & Total & $160(100.0 \%)$ & $160(100.0 \%)$ & & $158(100.0 \%)$ & $158(100.0 \%)$ & \\
\hline \multirow{6}{*}{$\begin{array}{l}\text { Frequency of } \\
\text { sex }\end{array}$} & Per day & $9(6.0 \%)$ & $3(2.0 \%)$ & \multirow{6}{*}{0.000} & $2(1.5 \%)$ & $3(2.1 \%)$ & \multirow{6}{*}{0.000} \\
\hline & Per week & $89(59.7 \%)$ & $63(41.2 \%)$ & & $63(46.0 \%)$ & $59(41.8 \%)$ & \\
\hline & Per month & $50(33.6 \%)$ & $64(41.8 \%)$ & & $69(50.4 \%)$ & $75(53.2 \%)$ & \\
\hline & Per year & $0(00 \%)$ & $12(7.8 \%)$ & & $0(00 \%)$ & $0(00 \%)$ & \\
\hline & No more & $1(0.7 \%)$ & $11(7.2 \%)$ & & $3(2.2 \%)$ & $4(2.8 \%)$ & \\
\hline & Total & $149(100.0 \%)$ & $153(100.0 \%)$ & & $137(100.0 \%)$ & $141(100.0 \%)$ & \\
\hline
\end{tabular}

Table 4: Comparison of risky behaviors before awareness of HIV status between HIV positive people and HIV negative/ignorant people.

\begin{tabular}{|c|c|c|c|c|}
\hline \multicolumn{2}{|l|}{ Risky behaviors } & HIV sero-positives & HIV sero-negatives/ignorants & P-value \\
\hline \multirow[t]{4}{*}{ Condom use } & Never & $62(39.2 \%)$ & $22(15.3 \%)$ & \multirow{4}{*}{0.000} \\
\hline & Often & $85(53.8 \%)$ & $77(53.5 \%)$ & \\
\hline & Always & $11(7.0 \%)$ & $45(31.3 \%)$ & \\
\hline & Total & $158(100.0 \%)$ & $144(100.0 \%)$ & \\
\hline \multirow{7}{*}{$\begin{array}{l}\text { Number of } \\
\text { sexual partners }\end{array}$} & 0 Partner & $2(1.3 \%)$ & $17(10.8 \%)$ & \multirow{7}{*}{0.000} \\
\hline & 1 partner & $65(40.6 \%)$ & $95(60.1 \%)$ & \\
\hline & 2 partners & $50(31.3 \%)$ & $31(19.6 \%)$ & \\
\hline & 3-4 partners & $30(18.8 \%)$ & $13(8.2 \%)$ & \\
\hline & 5-9 partners & $4(2.5 \%)$ & $1(0.6 \%)$ & \\
\hline & $\geq 10$ partners & $9(5.6 \%)$ & $1(0.6 \%)$ & \\
\hline & Total & $160(100.0 \%)$ & $158(100.0 \%)$ & \\
\hline \multirow{6}{*}{$\begin{array}{l}\text { Frequency of } \\
\text { sex }\end{array}$} & Per day & $9(6.0 \%)$ & $2(1.5 \%)$ & \multirow{6}{*}{0.006} \\
\hline & Per week & $89(59.7 \%)$ & $63(46.0 \%)$ & \\
\hline & Per month & $50(33.6 \%)$ & $69(50.4 \%)$ & \\
\hline & Per year & $0(00 \%)$ & $0(00 \%)$ & \\
\hline & No more sex & $1(0.7 \%)$ & $3(2.2 \%)$ & \\
\hline & Total & $149(100.0 \%)$ & $137(100.0 \%)$ & \\
\hline
\end{tabular}

sexual intercourse against $39.2 \%$ in HIV sero-positive participants. $31 \%$ of HIV sero-negative/sero-ignorant respondents always use condoms, while only $7 \%$ of HIV infected people always used condoms. There was a significant difference in condom usage between HIV negative/sero-ignorant and HIV positive participants before being aware of their HIV sero-status ( $p=0.0)$; see Table 3 and Table 4.

\section{Condom use after knowledge of HIV status}

After both groups were aware of their HIV sero-status, there was no significant difference in condom usage, $p=0.376$. So a risk reduction in PLWHA was noticed after awareness of their status $p=0.002$ (see Table 3 and Table 5 respectively).

\section{Number of sexual partners prior knowledge of HIV status}

In the group of HIV sero-negative/sero-ignorant peo- ple, $10.8 \%$ had no partner against only $1.3 \%$ in PLWHA before being aware of their HIV sero-status. This proportion of PLWHA may have acquired HIV through other route like transfusion of infected blood or contaminated needles. $60.1 \%$ of HIV sero-negative/sero-ignorant participants had one partner against $40.6 \%$ in HIV positive people. 53.1\% of PLWHA had between 2 and 9 partners against $31.25 \%$ in HIV sero-negative/sero-ignorant people. Up to $5.6 \%$ of HIV positive people had more than 10 sexual partners for only $0.6 \%$ in HIV negative/sero-ignorant group. Evidently, there was an association between HIV sero-status and the number of sexual partners; $p=$ 0.001 (see Table 3).

\section{Number of sexual partners after knowledge of HIV status}

After awareness of their HIV status, there was still a significant difference between HIV negative/sero-ignorant 
Table 5: Comparison of risky behaviors after awareness of HIV status between HIV positive and HIV negative/ignorant people.

\begin{tabular}{|c|c|c|c|c|}
\hline \multicolumn{2}{|l|}{ Risky bebaviors } & \multirow{2}{*}{$\begin{array}{l}\text { HIV sero-positives } \\
24(16.1 \%)\end{array}$} & \multirow{2}{*}{$\begin{array}{l}\text { HIV sero-negatives/ignorants } \\
28(18.9 \%)\end{array}$} & \multirow{2}{*}{$\begin{array}{l}\text { P-value } \\
0.376\end{array}$} \\
\hline Condom use & Never & & & \\
\hline & Often & $63(42.3 \%)$ & $70(47.3 \%)$ & \\
\hline & Always & $62(41.6 \%)$ & $50(33.8 \%)$ & \\
\hline & Total & $149(100.0 \%)$ & $148(100.0 \%)$ & \\
\hline \multirow{7}{*}{$\begin{array}{l}\text { Number of } \\
\text { sexual partners }\end{array}$} & 0 Partner & $22(13.8 \%)$ & $16(10.1 \%)$ & \multirow[t]{7}{*}{0.001} \\
\hline & 1 partner & $93(58.1 \%)$ & $125(79.1 \%)$ & \\
\hline & 2 partners & $29(18.1 \%)$ & $14(8.9 \%)$ & \\
\hline & 3-4 partners & $12(7.5 \%)$ & $3(1.9 \%)$ & \\
\hline & 5-9 partners & $2(1.3 \%)$ & $0(00 \%)$ & \\
\hline & $\geq 10$ partners & $2(1.3 \%)$ & $0(00 \%)$ & \\
\hline & Total & $160(100.0 \%)$ & $158(100.0 \%)$ & \\
\hline \multirow{6}{*}{$\begin{array}{l}\text { Frequency of } \\
\text { sex }\end{array}$} & Per day & $3(2.0 \%)$ & $3(2.1 \%)$ & \multirow[t]{6}{*}{0.003} \\
\hline & Per week & $63(41.2 \%)$ & $59(41.8 \%)$ & \\
\hline & Per month & $64(41.8 \%)$ & $75(53.2 \%)$ & \\
\hline & Per year & $12(7.8 \%)$ & $0(00 \%)$ & \\
\hline & No more sex & $11(7.2 \%)$ & $4(2.8 \%)$ & \\
\hline & Total & $153(100.0 \%)$ & $141(100.0 \%)$ & \\
\hline
\end{tabular}

people and HIV sero-positive with the number of sexual partners $p=0.001$. These data are presented in Table 5 . But as seen in Table 3, in PLWHA, there was an association between the number of partners and being aware or not of the HIV status ( $p=0.001$ ). $13.8 \%$ of PLWHA were without sexual partner after awareness of the HIV status against $1.3 \%$ before awareness. $5.6 \%$ of PLWHA had more than 10 partners before being aware they were HIV positive against $1.3 \%$ after they knew they were infected. The number of PLWHA with one partner before and after awareness increased from $40.6 \%$ to $58.1 \%$.

\section{Frequency of intercourse before awareness of HIV status}

Among HIV-infected subjects that we surveyed, $59.7 \%$ maintained weekly sex, 33.6\% monthly intercourse. $6 \%$ of this group was represented by PLWHA maintaining daily sex.

In the HIV negative/sero-ignorant group, $46 \%$ maintained weekly sex, $1.5 \%$ maintain daily sex and $2.2 \%$ were not sexually active. There was a weak association ( $p=0.006$ ) between HIV sero-status and the frequency of sex before knowledge of HIV status (see Table 4).

\section{Frequency of intercourse after awareness of HIV status}

After awareness of HIV sero-status, there was a significant association between HIV status and the frequency of sex; $p=0.003$ (Table 5). In the group of HIV positive participants, being aware of their status impacted their sex frequency, with $p=0.000$. Two percent maintained daily sex after they knew they were infected compare to $6 \%$ before awareness. A percentage of 7.2 of PLWHA was sexually inactive after awareness against $0.7 \%$ before (see Table 4 and Table 5).

\section{Concordance of HIV status in married or free union couples}

Among HIV sero-negative and HIV sero-ignorant we surveyed, $93 \%$ had sero-concordant partner while $7 \%$ had discordant partner. Among PLWHA in our sample, $55.45 \%$ were in sero-concordant couples while $44.55 \%$ were of sero-discordant couples.

\section{Discussion}

Our study described the level of compliance with HIV prevention behaviors by HIV-positive and HIV sero-negative/sero-ignorant of Yaounde. A comparison of HIV risk behavior among HIV sero-positive on one hand and the HIV sero-negative/sero-ignorant on the other was done.

A portion of HIV infected people (7\%) declared always using condoms during sexual activities. Given the safety of condoms (although not $100 \%$ efficient), and trusting their declaration we are inclined of postulating other routes of infection in this fraction of PLWH in Yaounde, probably from infected transfused blood. This raises the issue of blood transfusion safety and mainly the problem of quality control in blood banks.

In Yaounde, HIV-positive people used less condoms than HIV sero-negative/sero-ignorant. Yet they are the main vectors of HIV transmission. Some HIV-positive people continue to adopt risky behaviors, extending the HIV transmission chain. This phenomenon probably contributes to increase HIV prevalence in the city of Yaounde. This was also observed in the United States and elsewhere. Crepaz and Marks in 2002 reported that HIV continues to spread through sexual transmission and that one of the sources of this transmission is the sexual risk among people who know and are aware that they are HIV positive [22].

We have seen in this study that, condom use has increased in PLWHA after awareness of their HIV sero-status; probably due to advices received from health care providers during their follow up visit (treatment refill).

Increasing condom use after the establishment of 
anti-retroviral treatment has been confirmed by several studies, including those conducted in Europe and in rural areas of Uganda by Bunnell [19] who observed that after six months of taking ART, the consistent condom use had increased and the rate of unprotected sex with negative or unknown status partner had decreased. It has been shown nevertheless by several studies that initiating ART may have dual impact on risky behaviors: Higher unsafe sex among PLWHA on ART and several studies from Africa have found an increase in high risk sexual behavior among persons initiating ART [23-25]. On the other hand, ART initiation has lowered the risk behaviors among PLWHA [12,16,19,22,26-30].

Our results and examples of literature are relevant arguments on which we must rely for good promotion of positive HIV prevention strategy through the continuation of condom use beside the ART.

PLWHA, transmitters of HIV have more sexual partners than HIV sero-negative/sero-ignorant either before or after being aware they were infected, even before and during ART. Multi sexual - partnership is a risk factor for HIV transmission, known in increasing HIV incidence. It may be for this reason that the number of new cases of HIV infections remains high in Yaounde and continues to undermine the country's economy.

Precocity of sexual activity is one of the factors that promote sexual transmission of HIV because it increases the number of unsafe sex. We noted through this study that HIV status was positively associated with early sexual activity. Concretely, PLWHA were sexually more precocious than HIV sero-negative/sero-ignorant. This result is in agreement with those of the 2011 EDS nationally [4]. Given the risks associated with early sex precocity, prevention campaigns must continue to encourage young people to delay their first intercourse and seek to master the contextual factors and structure able to make this first experience safer for young people.

The precocity of sexual activity can be a cause and/ or a consequence of HIV infection. First, it is a risk factor for HIV and other people may decide to initiate intimate relations just after knowledge of their HIV status. But the limitation of this study is that it was not design to record the time of HIV infection and therefore we could not say with conviction that the early sexual relations in this particular case is a cause or a consequence of HIV infection because they are other infections routes.

We noted in this study that people infected with HIV were more likely to change their sexual behavior: adoption of less risky behaviors (condom usage, reduction of sexual partners...). This is due to the advice they receive during their visit at the health care center on the one hand. On the other hand, in case their status is known by the community or by regular or occasional partners, the self and social stigma of infection can reduce their desire for sexual intercourse.
The study revealed that Yaounde city dwellers and PLWHA in particular have good intentions of adopting preventive behaviors of HIV sero-positive. Good intention, while important and relevant, is not enough to fully resolve risk behaviors of HIV among PLWHA. Therefore, there is an urgent need to explore the determinants of risk behaviors and barriers to the adoption of preventive.

The overall limitation of this study is that it was done just in Yaounde (the capital city of Cameroon). Therefore, the findings cannot be generalized for the whole territory because of difference in cultural beliefs and socio-economics. Thus this study should be repeated in other cities with different socio-cultural background.

\section{Conclusions}

HIV positive people present more risky behaviors compared to HIV sero-negative/sero-ignorant people. PLWHA prove receptive to advice and after awareness of their status an improvement was noticeable in their behavior. Thus positive prevention method could be developed and implemented successfully in Cameroon in order to curb HIV sexual transmission. The national program against HIV/AIDS should enhance health promotion to reduce unsafe sexual behavior in PLWHA.

\section{Acknowledgements}

We especially thank the participants of this study and health officials of the study sites. We acknowledge as well the contribution of UCAC and CIRCB.

\section{Ethical Statement}

This research protocol received the ethical clearance from the Ethics Committee of the School of Health Sciences of the Catholic University of Central Africa. Informed written consent was obtained from each participant.

\section{References}

1. http://www.ebanque-pdf.com/fr_plan-strategique-nationalde-lutte-contre-le-sida-cameroun.html

2. (2006) Plan stratégique national de lutte contre le VIH/sida. CNLS.

3. (2010) Plan stratégique national de lutte contre le sida, le VIH et les autres IST. CNLS.

4. (2011) EDS-MICS 2011. Republique Du.

5. http://www.cnls.cm/docs/Rapport_GARP_2014_ Juin_2015_CNLS.pdf

6. (2013) Rapport annuel 2013 de la lutte contre le VIH/SIDA et les IST au Cameroun. CNLS.

7. (2010) Report on the global AIDS epidemic. Joint United Nations Programme on HIVIAIDS (UNAIDS).

8. Collins C, Morin SF, Shriver MD, Coates TJ (2000) Designing primary prevention for people living with HIVIAIDS. Center for AIDS Prevention Studies, University of California, San Francisco.

9. Centers for Disease Control and Prevention (CDC) (2003) Advancing HIV prevention: New strategies for a changing 
epidemic - United States, 2003. MMWR Morb Mortal Wkly Rep 52: 329-332.

10. Centers for Disease Control and Prevention (CDC), Health Resources and Services Administration, National Institutes of Health, HIV Medicine Association of the Infectious Diseases Society of America (2003) Incorporating HIV prevention into the medical care of persons living with HIV. Recommendations of CDC, the Health Resources and Services Administration, the National Institutes of Health, and the HIV Medicine Association of the Infectious Diseases Society of America. MMWR Recomm Rep 52: 1-24.

11. Auerbach JD (2004) Principles of positive prevention. J Acquir Immune Defic Syndr 37: S122-S125.

12. Kalichman S (2005) Positive prevention: Reducing HIV transmission among people living with HIVIAIDS. Storrs, Springer.

13. International HIVIAIDS Alliance (2007) Positive prevention: Prevention strategies for people with HIVIAIDS.

14. (2009) Moving forward on 'positive health, dignity and prevention' - people living with HIV set principles for engagement. Global Network of People Living with HIVIAIDS, UNAIDS.

15. Crepaz N, Lyles CM, Wolitski RJ, Passin WF, Rama SM, et al. (2006) Do prevention interventions reduce HIV risk behaviours among people living with HIV? A meta-analytic review of controlled trials. AIDS 20: 143-157.

16. Johnson BT, Carey MP, Chaudoir SR, Reid AE (2006) Sexual risk reduction for persons living with HIV: Research synthesis of randomized controlled trials, 1993 to 2004 . J Acquir Immune Defic Syndr 41: 642-650.

17. Gilliam PP, Straub DM (2009) Prevention with positives: A review of published research, 1998-2008. J Assoc Nurses AIDS Care 20: 92-109.

18. (2004) HIV prevention in the era of expanded treatment access. Global HIV Prevention Working Group.

19. Bunnell R, Ekwaru JP, Solberg P, Wamai N, Bikaako-Kajura W, et al. (2006) Changes in sexual behavior and risk of HIV transmission after antiretroviral therapy and prevention interventions in rural Uganda. AIDS 20: 85-92.

20. Kennedy CE, Medley AM, Sweat MD, O'Reilly KR (2010) Behavioural interventions for HIV positive prevention in de- veloping countries: A systematic review and meta-analysis. Bull World Health Organ 88: 615-623.

21. http://www.cnls.cm/docs/publications/Enquete/rapport etudes_cap_routiers_moto-action_cpc_2015.pdf

22. Crepaz N, Marks G (2002) Towards an understanding of sexual risk behavior in people living with HIV: A review of social, psychological, and medical findings. AIDS 16: 135149.

23. Diabate S, Alary M, Koffi CK (2008) Short-term increase in unsafe sexual behaviour after initiation of HAART in Cote d'Ivoire. AIDS 22: 154-156.

24. Eisele TP, Mathews C, Chopra M, Brown L, Silvestre E, et al. (2008) High levels of risk behavior among people living with HIV Initiating and waiting to start antiretroviral therapy in Cape Town South Africa. AIDS Behav 12: 570-577.

25. Yaya I, Saka B, Landoh DA, Patchali PM, Makawa MS, et al. (2014) Sexual risk behavior among people living with HIV and AIDS on antiretroviral therapy at the regional hospital of Sokodé, Togo. BMC Public Health 14: 636.

26. Marks G, Crepaz N, Senterfitt JW, Janssen RS (2005) Meta-analysis of high-risk sexual behavior in persons aware and unaware they are infected with HIV in the United States: Implications for HIV prevention programs. J Acquir Immune Defic Syndr 39: 446-453.

27. Cornman DH, Kiene SM, Christie S, Fisher WA, Shuper $\mathrm{PA}$, et al. (2008) Clinic-based intervention reduces unprotected sexual behavior among HIV-infected patients in Kwazulu-Natal, South Africa: Results of a pilot study. J Acquir Immune Defic Syndr 48: 553-560.

28. Eisele TP, Mathews C, Chopra M, Lurie MN, Brown L, et al. (2009) Changes in risk behavior among HIV-positive patients during their first year of antiretroviral therapy in Cape Town South Africa. AIDS Behav 13: 1097-1105.

29. Ndziessi G, Cohen J, Kouanfack C, Boyer S, Moatti JP, et al. (2013) Changes in sexual activity and risk behaviors among PLWHA initiating ART in rural district hospitals in Cameroon - data from the STRATALL ANRS 12110/ESTHER trial. AIDS Care 25: 347-355.

30. Peltzer K, Ramlagan S (2010) Safer sexual behaviours after 1 year of antiretroviral treatment in KwaZulu-Natal, South Africa: A prospective cohort study. Sex Health 7: 135-141. 